\title{
Identfication of key miRNAs in pancreatitis using bioinformatics analysis of microarray data
}

\author{
DADONG WANG ${ }^{1}$, ZI-MAN ZHU ${ }^{1}$, YU-LIANG TU ${ }^{1}$, CHUN-QING DOU $^{1}$, YONG XU $^{2}$, XIANG-LONG TAN ${ }^{2}$, \\ MING-MING HAN ${ }^{1}$, ZHUANG-JIE YANG ${ }^{1}, \mathrm{XIN} \mathrm{JIN}^{1}$, BAO ZHANG ${ }^{1}$, SHOUWANG CAI $^{3}$ and ZHI-WEI LIU ${ }^{3}$ \\ ${ }^{1}$ Department of Hepatobiliary Surgery, The First Affiliated Hospital of Chinese PLA General Hospital, Beijing 100048; \\ Departments of ${ }^{2}$ Second Surgical Oncology and ${ }^{3}$ Hepatobiliary Surgery, Chinese PLA General Hospital, Beijing 100853, P.R. China
}

Received September 6, 2015; Accepted September 13, 2016

DOI: $10.3892 / \mathrm{mmr} .2016 .5928$

\begin{abstract}
Pancreatitis is a type of inflammation in the pancreas, which frequently occurs due to alcohol and gallstones. The present study aimed to identify pancreatitis-associated microRNAs (miRNAs) by analyzing the microarray of GSE24279. GSE24279 was downloaded from the Gene Expression Omnibus, composed of a collective of 27 pancreatitis and 22 normal control samples. The differentially expressed miRNAs (DE-miRNAs) in pancreatitis samples were screened using the Limma package in Bioconductor. Subsequently, target genes of the DE-miRNAs were predicted using the miRecords and miRWalk databases. Their potential functions were analyzed by functional and pathway enrichment analysis using the Database for Annotation, Visualization and Integrated Discovery online tool. Finally, pancreatitis-associated genes among the target genes identified were searched using the Comparative Toxicogenomics Database, and a regulatory network of pancreatitis-associated genes and their target miRNAs were constructed using Cytoscape software. A total 14 upregulated and 39 downregulated miRNAs were identified in pancreatitis samples compared with control samples and 290 target genes of DE-miRNAs were determined. Cyclin D1 $(C C N D 1)$, v-akt murine thymoma viral oncogene homolog 2 (AKT2), cyclin-dependent kinase 6 (CDK6) and SMAD family member 2 (SMAD2) were involved in the pathway of pancreatic cancer. Among the target genes, 279 genes were pancreatitis-associated genes, which in turn were targeted by 37 miRNAs in the regulatory network. Hsa-miR-15a, hsa-miR-16, hsa-miR-155, hsa-miR-375 and hsa-miR-429 in particular may be involved in pancreatitis by targeting genes
\end{abstract}

Correspondence to: Dr Shouwang Cai or Dr Zhi-Wei Liu, Department of Hepatobiliary Surgery, Chinese PLA General Hospital, 28 Fuxing Road, Haidian, Beijing 100853, P.R. China E-mail: caisw8077.cai@vip.sina.com

E-mail: zhiweiliuzzz@hotmail.com

Key words: pancreatitis, differentially expressed miRNAs, target genes, enrichment analysis, regulatory network in the regulatory network, including $h s a-m i R-15 a \rightarrow C C N D 1$, hsa-miR-16 $\rightarrow C C N D 1$, hsa-miR-155 $\rightarrow$ CCND1/SMAD2, $h s a-m i R-375 \rightarrow A K T 2 / C D K 6$ and $h s a-m i R-429 \rightarrow C C N D 1$. The above miRNAs and their targets may contribute to the pathogenesis of pancreatitis; therefore, they may be potential therapeutic targets.

\section{Introduction}

As a type of inflammation in the pancreas, pancreatitis is frequently due to excessive alcohol consumption and gallstones (1-3). Patients with pancreatitis often suffer from upper abdominal pain, nausea and vomiting $(4,5)$ and may develop complications, including diabetes, infection and bleeding (6-8). Globally, the pancreatitis-associated deaths in 2013 were 123,000, up from 83,000 deaths in 1990 (9). Therefore, it is urgent to investigate the underlying molecular mechanisms that lead to pancreatitis.

MicroRNAs (miRNAs) are 22-nucleotide single-stranded and small non-coding RNAs that regulate post-transcriptional expression of genes in eukaryotes and function in diverse biological processes $(10,11)$. miRNAs, which are more stable compared with mRNAs, which is essential for the robustness of diagnostic assays (12). In comparison with normal pancreatic tissue, several miRNAs, including miR-99, miR-100, miR-125a, miR-199a-1, miR-199a-2 have been previously identified to be overexpressed in pancreatic cancer and in chronic pancreatitis (13). In pancreatic cancer cells, tumor-suppressing miR-96 may act as a novel therapeutic marker for the treatment of pancreatic cancer via targeting the Kirsten rat sarcoma viral oncogene homolog oncogene (14). $C D 40$ targeted by $m i R-224$ and $m i R-486$ may be of importance to the progression of pancreatic ductal adenocarcinomas (PDACs) and may have diagnostic and therapeutic potential in PDACs (15). Cell division cycle 25B, which may contribute to proliferation of PDACs, has been identified as a novel target of $m i R-148 a$ (16). A previous study indicated that $m i R-10 a$ was upregulated in various pancreatic cancers and correlated with the invasive potential of pancreatic cancer cells by inhibiting homeobox A1 (17). In the present study, differentially expressed miRNAs (DE-miRNAs) in pancreatitis were screened using miRNA expression profile of GSE24279. The genes targeted by DE-miRNAs were predicted and their 
potential functions were analyzed by functional and pathway enrichment analysis. Subsequently, pancreatitis-associated genes were identified from the target genes and the regulatory networks of pancreatitis-associated genes and miRNAs that targeted them were constructed.

\section{Materials and methods}

Microarray data. The miRNA expression profile of GSE24279 was downloaded from the Gene Expression Omnibus (www.ncbi.nlm.nih.gov/geo/), which was based on the platform of GPL10944 febit human miRBase version 11. A collective of 27 pancreatitis and 22 normal control samples were selected from GSE24279 to investigate the mechanisms of pancreatitis.

Screening for DE-miRNAs. Using the vsn package (18) in Bioconductor, version 2.7, microarray data was preprocessed using robust estimation of variance-stabilizing and calibrating transformations to obtain an expression matrix of miRNAs. The limma package (19) in Bioconductor was used to screen the DE-miRNAs between pancreatitis samples and control samples. The P-values of miRNAs were calculated using the t-test function in the limma package and adjusted for multiple comparisons using the Benjamini \& Hochberg method (20). The adjusted $\mathrm{P}<0.05$ and $\log _{2}$ fold-change (FC) $\mid \geq 0.58$ (corresponded to 1.5 -fold) were used as the cut-off criteria.

Analysis of genes targeted by DE-miRNAs. The genes targeted by DE-miRNAs were predicted using the miRecords (http://c1.accurascience.com/miRecords/) (21) and miRWalk (www.umm.uni-heidelberg.de/apps/zmf/mirwalk/) (22) databases. A DE-miRNA-gene pair was required to appear in at least one database as a filtering condition.

Functional and pathway enrichment analysis. Gene Ontology (GO) analysis was used to predict the potential functions of the gene products, including molecular function (MF), biological process (BP) and cellular component (CC) categories (23). The Kyoto Encyclopedia of Genes and Genomes (KEGG), which consists of the PATHWAY, GENES and LIGAND databases was used to identify molecular functions (24). Using the Database for Annotation, Visualization and Integrated Discovery (DAVID) (25) online tool, GO and KEGG pathway enrichment analyses were performed for the genes targeted by the DE-miRNAs. Parameters of EASE $\leq 0.05$ and count $\geq 2$ were used as the thresholds. The remaining parameters were set to defaults.

Regulatory network construction. There may be pancreatitis-associated genes among the target genes of DE-miRNAs, and it is suggested that miRNAs that targeted them may have been involved in pancreatitis progression. Therefore, the Comparative Toxicogenomics Database (CTD; ctd.mdibl.org) (26) was used to identify pancreatitis-associated genes. Next, the regulatory network of pancreatitis-associated genes and miRNAs that targeted them were visualized using Cytoscape software, version 2.8 (www.cytoscape.org) (27).

\section{Results}

Analysis of DE-miRNAs and their target genes. There were 14 upregulated and 39 downregulated miRNAs screened in pancreatitis samples compared with the control samples. There were more downregulated miRNAs compared with upregulated miRNAs. The heat map of DE-miRNAs is presented in Fig. 1. A total 424 DE-miRNA-gene pairs were identified in the miRecords and miRWalk databases and 290 target genes of DE-miRNAs were obtained.

Functional and pathway enrichment analysis. The functions of target genes were predicted using the DAVID online tool, and the GO and KEGG pathway enrichment analyses. The enriched GO functions for the target genes are presented in Table I, including the positive regulation of macromolecule metabolic process $\left(\mathrm{P}=1.20 \times 10^{-32}\right)$ in the $\mathrm{BP}$ category, nuclear lumen $\left(\mathrm{P}=1.25 \times 10^{-14}\right)$ in the $\mathrm{CC}$ category and sequence-specific DNA binding $\left(\mathrm{P}=2.73 \times 10^{-18}\right)$ in the MF category. The enriched KEGG pathways for target genes included pathways in cancer $\left(\mathrm{P}=5.32 \times 10^{-16}\right)$, focal adhesion $\left(\mathrm{P}=1.70 \times 10^{-7}\right)$ and pancreatic cancer $\left(\mathrm{P}=3.08 \times 10^{-5}\right.$; Table II $)$. Cyclin D1 (CCNDI), v-akt murine thymoma viral oncogene homolog 2 (AKT2), cyclin-dependent kinase 6 (CDK6) and SMAD family member 2 (SMAD2) were specifically involved in the pancreatic cancer pathway.

Regulatory network analysis. The CTD database revealed that a total of 279 genes out of the 290 target genes were associated with pancreatitis and were targeted by 37 miRNAs. The regulatory network of pancreatitis-associated genes and the miRNAs that targeted them is presented in Fig. 2. It is of note that $h s a-m i R-15 a$ targeted 56 genes, including CCND1, hsa-miR-16 targeted 63 genes including CCND1, hsa-miR-155 targeted 20 genes, including CCNDl and SMAD2, hsa-miR-375 targeted 44 genes, including AKT2 and CDK6 and hsa-miR-429 targeted 59 genes, including CCNDI Additionally, hsa-miR-16 targeted the highest number of genes in the regulatory network (Fig. 3).

\section{Discussion}

In the present study, 14 upregulated and 39 downregulated miRNAs were identified in the screened pancreatitis samples compared with the control samples. A total 424 DE-miRNA-gene pairs were identified in the miRecords and miRWalk databases and 290 target genes of DE-miRNAs were obtained. It is of note that $C C N D 1, A K T 2$, $C D K 6$ and SMAD2 were involved in the pancreatic cancer pathway. Among the target genes, 279 genes were pancreatitis-associated genes, which were targeted by 37 miRNAs in the regulatory network.

$m i R-155$, which has abnormal expression in the early stage of pancreatic cancer, may be used as a biomarker for intraductal papillary mucinous neoplasms (28). miR-155, $m i R-203, m i R-210$ and $m i R-222$ have an oncogenic function in the development and progression of pancreatic cancer by targeting several genes; therefore, it is possible that the tumorigenesis and tumor progression of PDAC was influenced by a complex signaling network (29). $m i R-15 a$ directly 


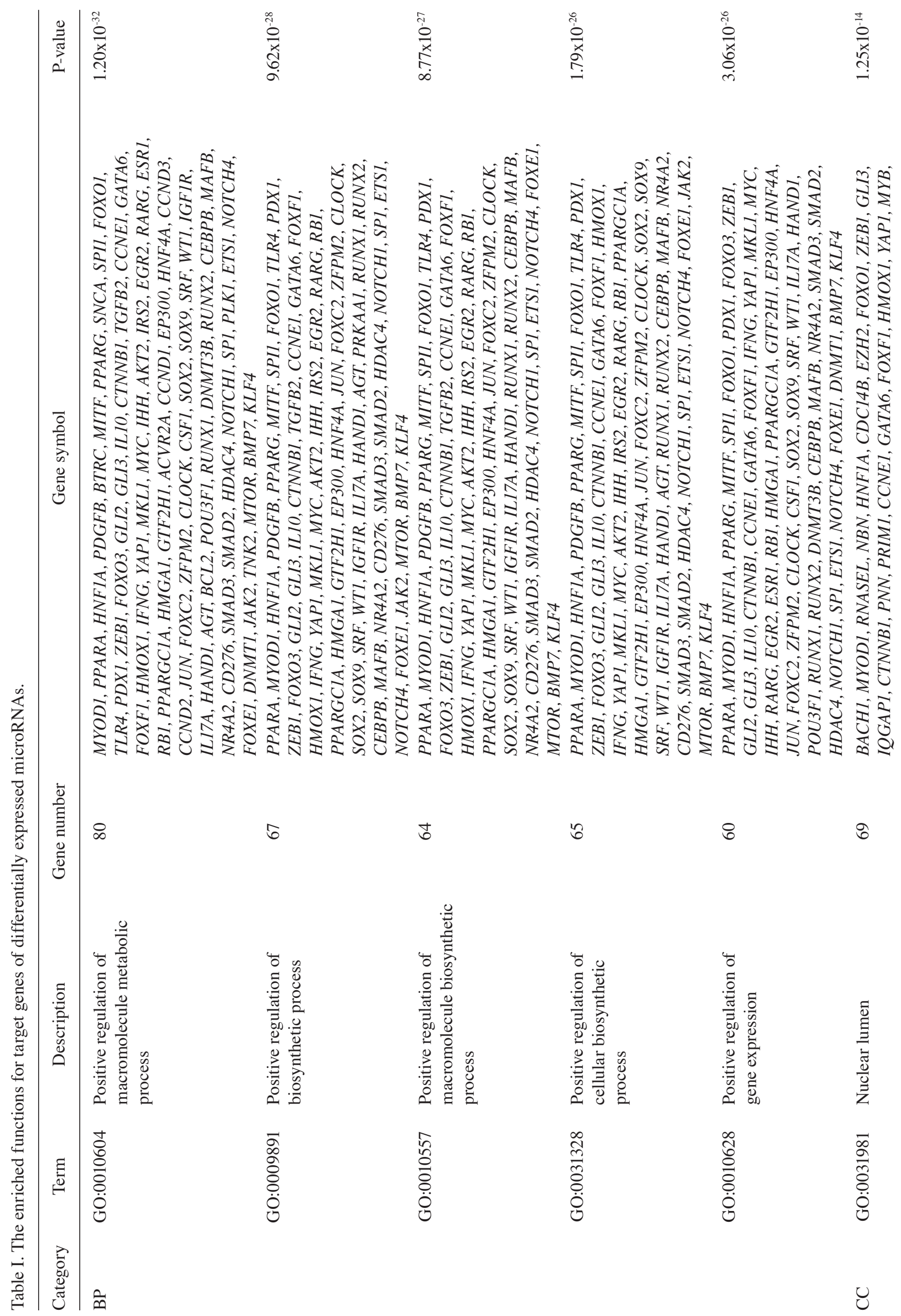




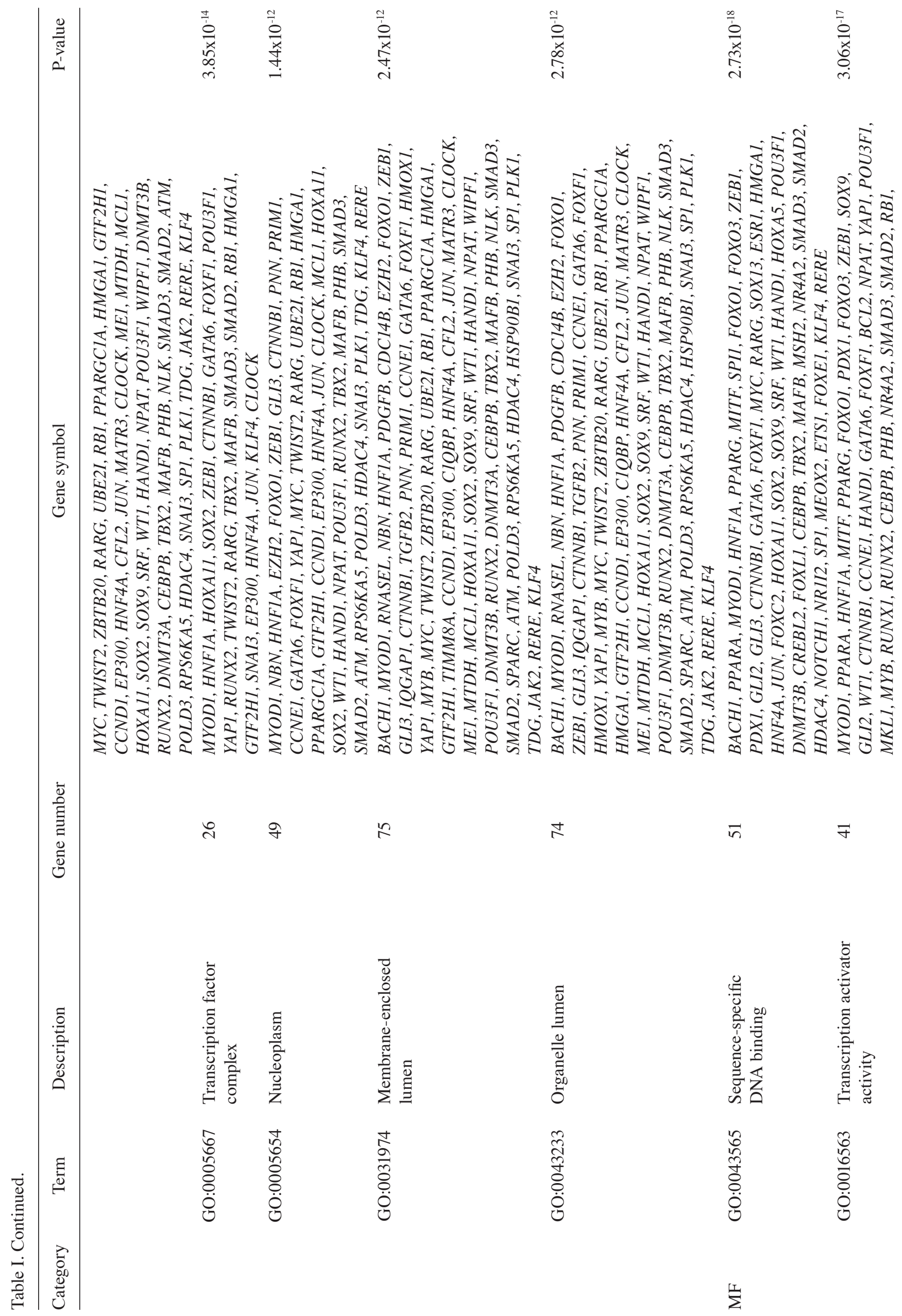




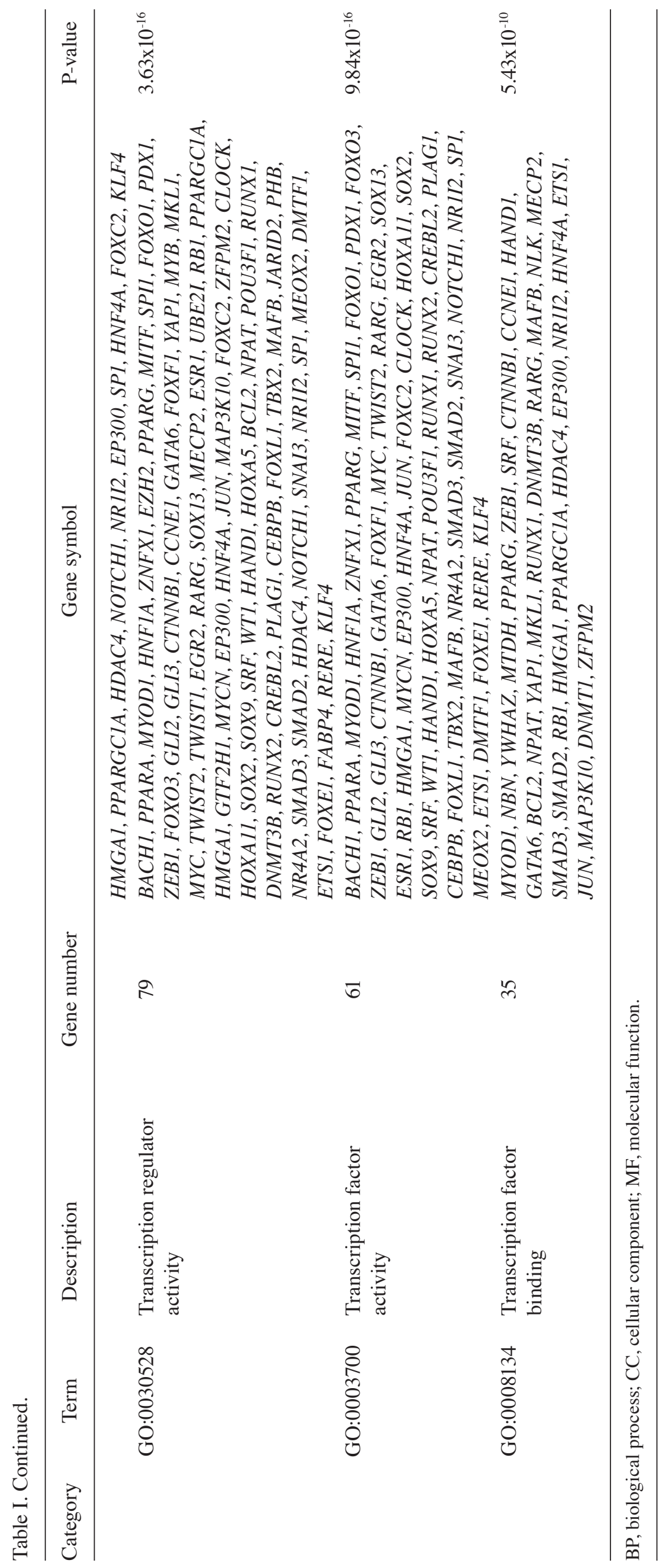




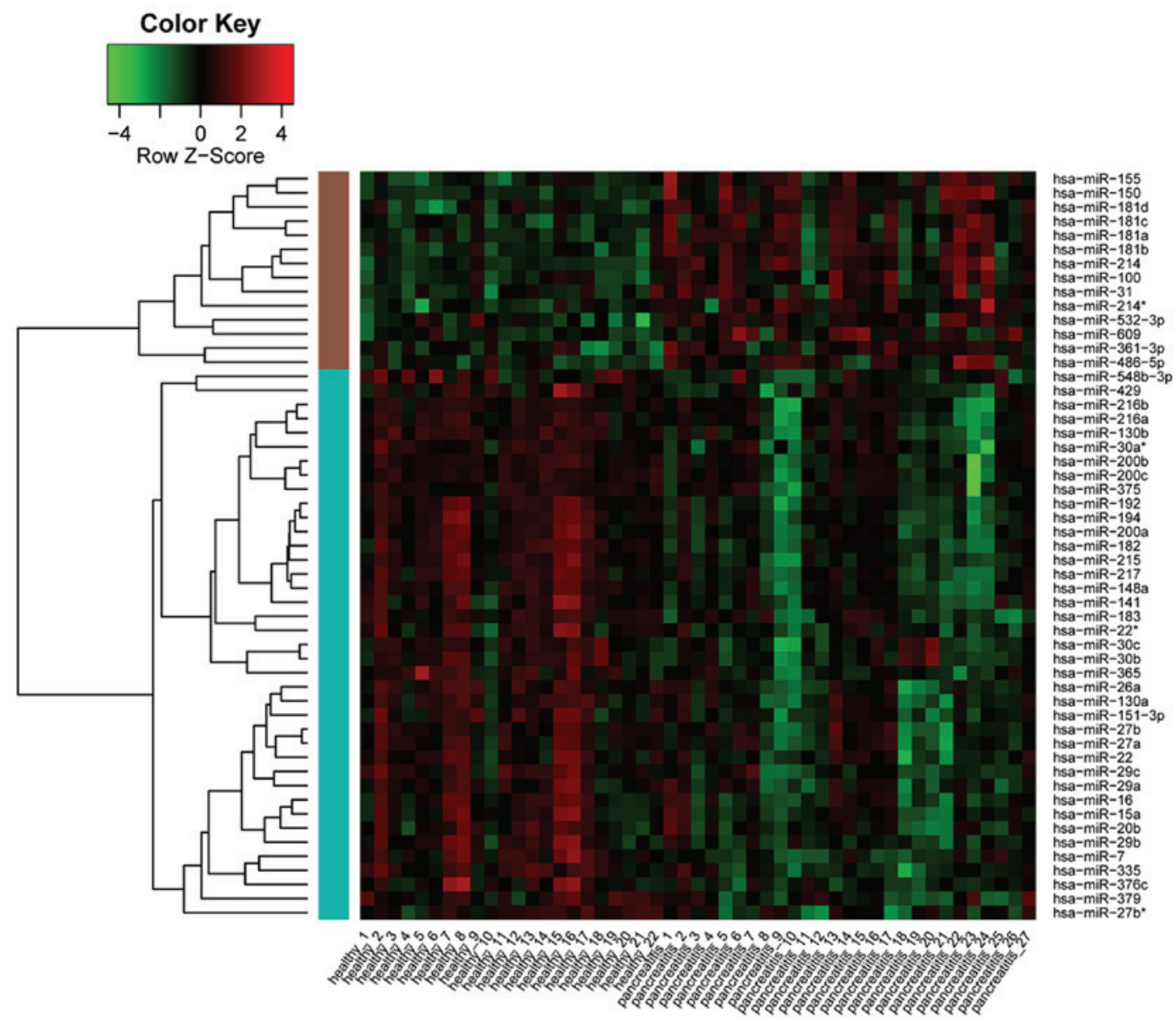

Figure 1. Heat map of differentially expressed miRNAs. Red indicates upregulated miRNAs. Green indicates downregulated miRNAs. miRNA, microRNA.

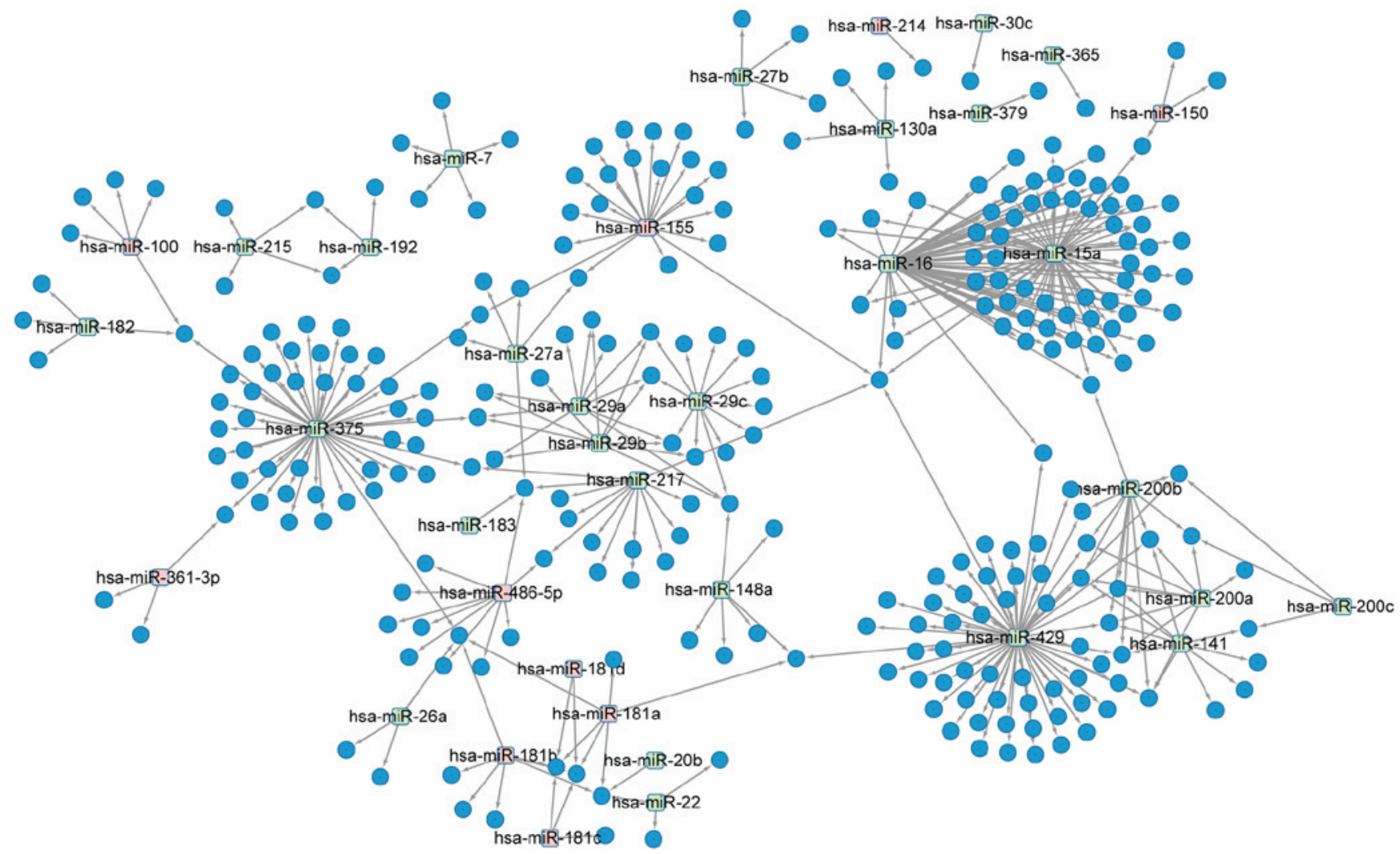

Figure 2. Regulatory network of pancreatitis-associated genes and their target miRNAs. Circle nodes indicate pancreatitis-associated genes. Square nodes represent differentially expressed miRNAs. Red nodes stand for upregulated miRNAs and green nodes for down-regulated miRNAs. miRNA, microRNA. 


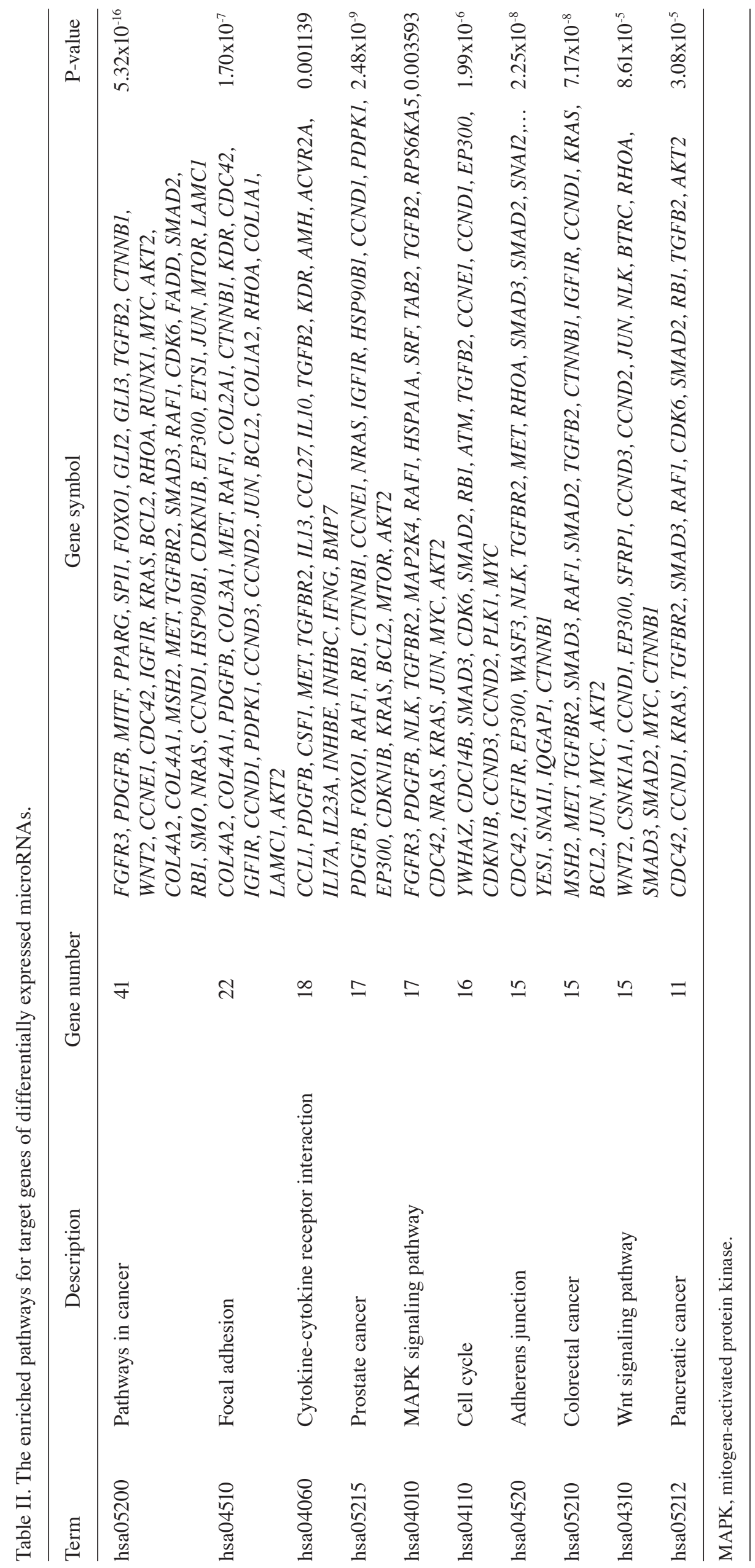




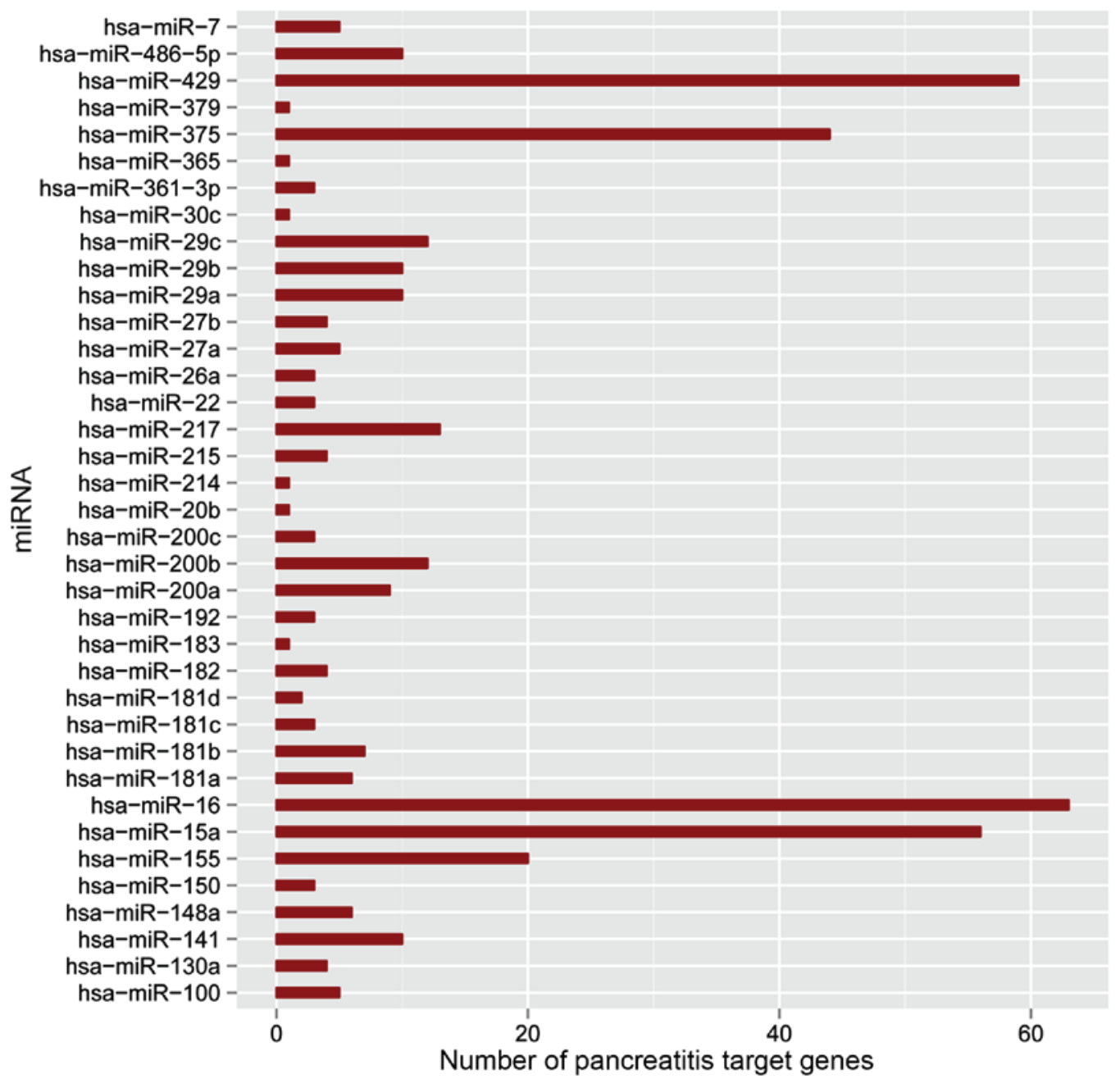

Figure 3. The number of pancreatitis-associated genes targeted by each differentially expressed miRNA. miRNA, microRNA.

targeted multiple pancreatic cancer-associated genes and its downregulation may aid the proliferation of pancreatic cancer cells, indicating that it may be used as a novel therapeutic target for the disease (30). Pathway enrichment revealed that CCND1 was also involved in pancreatic cancer progression. Previous studies determined that $C C N D 1$, which is frequently co-overexpressed with $C C N D 3$ (31), integrated extracellular mitogenic signaling and impacted tumor cell migration in PDAC (32). Upregulated CCND1 promoted chemoresistance of pancreatic cancer cells by facilitating cell proliferation and suppression of drug-induced apoptosis (33). As a component of the E-cadherin-catenin cell adhesion complex, $\beta$-catenin may also contribute to the tumorigenesis of pancreatic cancer primarily by transactivation of CCNDI (34). In the regulatory network, $h s a-m i R-15 a, h s a-m i R-16, h s a-m i R-155$ and $h s a-m i R-429$ targeted more genes than other miRNAs, and $C C N D 1$ was a common target gene. This indicated that hsa-miR-15a, hsa-miR-16, hsa-miR-155 and $h s a-m i R-429$ may be important for the regulation of pancreatitis via $C C N D 1$.

In PDAC, SMAD protein expression levels in stromal fibroblasts and in epithelial tumor cells was correlated with both stromal features and a shorter postsurgical overall survival (35). Overexpression of the embryonic protein Nodal may lead to a metastatic phenotype in pancreatic carcinoma cells by the SMAD2/3 pathway. Therefore, Nodal may be a potential target for treatment of pancreatic cancer (36). A previous study determined that the expression levels of transforming growth factor $\beta 1$ and SMAD2 in pancreatic adenocarcinoma were higher when compared with the normal control pancreatic parenchyma and their expression correlated with the tumor stage (37). In the present study, SMAD2 was enriched in the pathway of pancreatic cancer. In addition, $S M A D 2$ was targeted by $h s a-m i R-155$ in the regulatory network. Therefore, $h s a-m i R-155$ may also function in pancreatitis by mediating $S M A D 2$.

A previous study indicated that the anticancer agent benzyl isothiocyanate may inhibit the proliferation of pancreatic cancer cells via regulation of the expression levels of $m i R-375$ and $m i R-221$ (38). Elevated $m i R-375$ affected proliferation, apoptosis and cell cycle distribution of pancreatic cancer cells; therefore, $m i R-375$ may contribute to novel treatments for pancreatic cancer (39). Pathway enrichment also indicated that $A K T 2$ and $C D K 6$ were involved in pancreatic cancer progression. AKT2 is frequently activated by upstream perturbations of the phosphatidylinositol 3-kinase (PI3K)/AKT pathway, which may contribute to the pathogenesis of highly aggressive pancreatic cancer (40). It has been determined that suppression of extracellular signal-regulated 
kinase and PI3K/AKT pathways activate forkhead members of the class $\mathrm{O}(F O X O)$ transcription factor and strengthen transcriptional activity of sulforaphane-induced $F O X O$, resulting in cell cycle arrest and cell apoptosis in pancreatic cancer (41). Downregulation of CDK6 and p16 may be involved in cell cycle progression and transformation of endocrine tumors, including pancreatic endocrine neoplasms (42). Overexpression of $C D K 4$ and $C D K 6$ may result in a stronger response in patients with pancreatic neuroendocrine tumors treated with CDK4/6 inhibitors (43). In the regulatory network constructed in the present study, hsa-miR-375 targeted 44 genes, including AKT2 and CDK6, suggesting that $h s a-m i R-155$ targeting $A K T 2$ and $C D K 6$ may also contribute to pancreatitis.

In conclusion, the present study performed a comprehensive bioinformatics analysis, and identified 14 upregulated and 39 downregulated miRNAs in pancreatitis samples compared with control samples. Additionally, hsa-miR-15a, hsa-miR-16 and $h s a-m i R-429$ were determined to target CCND1, hsa-miR-155 targeted CCND1 and SMAD2 and hsa-miR-375 targeted $A K T 2$ and $C D K 6$; therefore, these miRNAs may contribute to the pathogenesis of pancreatitis and be potential therapeutic targets. However, these predictions require further experimental validation in future studies.

\section{References}

1. Apte MV, Pirola RC and Wilson JS: Pancreas: Alcoholic pancreatitis-it's the alcohol, stupid. Nat Rev Gastroenterol Hepatol 6: 321-322, 2009.

2. Yadav D, Hawes RH, Brand RE, Anderson MA, Money ME, Banks PA, Bishop MD, Baillie J, Sherman S, DiSario J, et al: Alcohol consumption, cigarette smoking, and the risk of recurrent acute and chronic pancreatitis. Arch Intern Med 169: 1035-1045, 2009.

3. Hofmeyr S, Meyer C and Warren BL: Serum lipase should be the laboratory test of choice for suspected acute pancreatitis. S Afr J Surg 52: 72-75, 2014.

4. Turner B: Acute pancreatitis: Symptoms, diagnosis and management. Nurs Times 99: 38-40, 2003.

5. Banks PA and Freeman ML; Practice Parameters Committee of the American College of Gastroenterology: Practice guidelines in acute pancreatitis. Am J Gastroenterol 101: 2379-2400, 2006.

6. Lipshutz GS and Wilkinson AH: Pancreas-kidney and pancreas transplantation for the treatment of diabetes mellitus. Endocrinol Metab Clin North Am 36: 1015-1038, 2007.

7. Tien YW, Lee PH, Yang CY, Ho MC and Chiu YF: Risk factors of massive bleeding related to pancreatic leak after pancreaticoduodenectomy. J Am Coll Surg 201: 554-559, 2005.

8. Marik PE and Zaloga GP: Meta-analysis of parenteral nutrition versus enteral nutrition in patients with acute pancreatitis. BMJ 328: 1407, 2004

9. GBD 2013 Mortality and Causes of Death Collaborators: Global, regional, and national age-sex specific all-cause and cause-specific mortality for 240 causes of death, 1990-2013: A systematic analysis for the Global Burden of Disease Study 2013 Lancet 385: 117-171, 2015.

10. Bartel DP: MicroRNAs: Target recognition and regulatory functions. Cell 136: 215-233, 2009.

11. Lund E, Güttinger S, Calado A, Dahlberg JE and Kutay U: Nuclear export of microRNA precursors. Science 303: 95-98, 2004.

12. Bauer AS, Keller A, Costello E, Greenhalf W, Bier M, Borries A, Beier M, Neoptolemos J, Büchler M, Werner J, et al: Diagnosis of pancreatic ductal adenocarcinoma and chronic pancreatitis by measurement of microRNA abundance in blood and tissue. PLoS One 7: e34151, 2012.

13. Bloomston M, Frankel WL, Petrocca F, Volinia S, Alder H, Hagan JP, Liu CG, Bhatt D, Taccioli C and Croce CM: MicroRNA expression patterns to differentiate pancreatic adenocarcinoma from normal pancreas and chronic pancreatitis. JAMA 297: 1901-1908, 2007.
14. Yu S, Lu Z, Liu C, Meng Y, Ma Y, Zhao W, Liu J, Yu J and Chen J: miRNA-96 suppresses KRAS and functions as a tumor suppressor gene in pancreatic cancer. Cancer Res 70: 6015-6025, 2010.

15. Mees ST, Mardin WA, Sielker S, Willscher E, Senninger N, Schleicher C, Colombo-Benkmann M and Haier J: Involvement of CD40 targeting miR-224 and miR-486 on the progression of pancreatic ductal adenocarcinomas. Ann Surg Oncol 16: 2339-2350, 2009.

16. Liffers ST, Munding JB, Vogt M, Kuhlmann JD, Verdoodt B, Nambiar S, Maghnouj A, Mirmohammadsadegh A, Hahn SA and Tannapfel A: MicroRNA-148a is down-regulated in human pancreatic ductal adenocarcinomas and regulates cell survival by targeting CDC25B. Lab Invest 91: 1472-1479, 2011.

17. Ohuchida K, Mizumoto K, Lin C, Yamaguchi H, Ohtsuka T, Sato N, Toma H, Nakamura M, Nagai E, Hashizume M and Tanaka M: MicroRNA-10a is overexpressed in human pancreatic cancer and involved in its invasiveness partially via suppression of the HOXA1 gene. Ann Surg Oncol 19: 2394-2402, 2012.

18. Huber W, Von Heydebreck A, Sültmann H, Poustka A and Vingron M: Variance stabilization applied to microarray data calibration and to the quantification of differential expression. Bioinformatics 18 (Suppl 1): S96-S104, 2002.

19. Smyth G: Limma: Linear models for microarray data. In: Bioinformatics and Computational Biology Solutions Using R and Bioconductor. R Gentleman, V Carey, S Dudoit, R Irizarry, W Huber (eds). Springer Science \& Business Media, New York, NY, pp397-420, 2005.

20. Benjamini Y: Discovering the false discovery rate. J Royal Stat Soc: Series B (Statistical Methodology) 72: 405-416, 2010.

21. Xiao F, Zuo Z, Cai G, Kang S, Gao X and Li T: miRecords: An integrated resource for microRNA-target interactions. Nucleic Acids Res 37 (Database issue): D105-D110, 2009.

22. Dweep H, Sticht C, Pandey P and Gretz N: miRWalk-database: Prediction of possible miRNA binding sites by 'walking' the genes of three genomes. J Biomed Inform 44: 839-847, 2011.

23. Tweedie S, Ashburner M, Falls K, Leyland P, McQuilton P, Marygold S, Millburn G, Osumi-Sutherland D, Schroeder A, Seal R, et al: FlyBase: Enhancing Drosophila gene ontology annotations. Nucleic Acids Res 37 (Database issue): D555-D559, 2009.

24. Kanehisa M and Goto S: KEGG: Kyoto encyclopedia of genes and genomes. Nucleic Acids Res 28: 27-30, 2000.

25. Huang da W, Sherman BT and Lempicki RA: Systematic and integrative analysis of large gene lists using DAVID bioinformatics resources. Nat Protoc 4: 44-57, 2009.

26. Davis AP, Grondin CJ, Lennon-Hopkins K, Saraceni-Richards C Sciaky D, King BL, Wiegers TC and Mattingly CJ: The Comparative Toxicogenomics Database's 10th year anniversary: Update 2015. Nucleic Acids Res 43 (Database issue): D914-D920, 2015.

27. Saito R, Smoot ME, Ono K, Ruscheinski J, Wang PL, Lotia S, Pico AR, Bader GD and Ideker T: A travel guide to Cytoscape plugins. Nat Methods 9: 1069-1076, 2012

28. Habbe N, Koorstra JB, Mendell JT, Offerhaus GJ, Ryu JK Feldmann G, Mullendore ME, Goggins MG, Hong SM and Maitra A: MicroRNA miR-155 is a biomarker of early pancreatic neoplasia. Cancer Biol Ther 8: 340-346, 2009.

29. Greither T, Grochola LF, Udelnow A, Lautenschläger C, Würl P and Taubert H: Elevated expression of microRNAs 155, 203, 210 and 222 in pancreatic tumors is associated with poorer survival. Int J Cancer 126: 73-80, 2010.

30. Zhang XJ, Ye H, Zeng CW, He B, Zhang $\mathrm{H}$ and Chen YQ: Dysregulation of miR-15a and miR-214 in human pancreatic cancer. J Hematol Oncol 3: 46, 2010.

31. Ebert MP, Hernberg S, Fei G, Sokolowski A, Schulz HU, Lippert $\mathrm{H}$ and Malfertheiner P: Induction and expression of cyclin D3 in human pancreatic cancer. J Cancer Res Clin Oncol 127: 449-454, 2001.

32. Radulovich N, Pham NA, Strumpf D, Leung L, Xie W, Jurisica I and Tsao MS: Differential roles of cyclin D1 and D3 in pancreatic ductal adenocarcinoma. Mol Cancer 9: 24, 2010.

33. Biliran H Jr, Wang Y, Banerjee S, Xu H, Heng H, Thakur A Bollig A, Sarkar FH and Liao JD: Overexpression of cyclin D1 promotes tumor cell growth and confers resistance to cisplatin-mediatedapoptosis in anelastase-myctransgene-expressing pancreatic tumor cell line. Clin Cancer Res 11: 6075-6086, 2005.

34. Qiao Q, Ramadani M, Gansauge S, Gansauge F, Leder G and Beger HG: Reduced membranous and ectopic cytoplasmic expression of beta-catenin correlate with cyclin D1 overexpression and poor prognosis in pancreatic cancer. Int J Cancer 95: 194-197, 2001. 
35. Handra-Luca A, Hammel P, Sauvanet A, Ruszniewski P and Couvelard A: Tumoral epithelial and stromal expression of SMAD proteins in pancreatic ductal adenocarcinomas. J Hepatobiliary Pancreat Sci 20: 294-302, 2013.

36. Duan W, Li R, Ma J, Lei J, Xu Q, Jiang Z, Nan L, Li X, Wang Z, Huo X, et al: Overexpression of Nodal induces a metastatic phenotype in pancreatic cancer cells via the $S \operatorname{mad} 2 / 3$ pathway. Oncotarget 6: 1490-1506, 2015.

37. Pan, X, Wang X, Wang Z, Zhu Q and Han Y: Expression of Smad 2 and TGF $\beta 1$ in human pancreatic carcinoma tissues and its significance. Prog Mod Biomed 6: 032, 2012.

38. Basu A, Alder H, Khiyami A, Leahy P, Croce CM and Haldar S: MicroRNA-375 and MicroRNA-221 Potentia noncoding RNAs associated with antiproliferative activity of Benzyl isothiocyanate in pancreatic cancer. Genes Cancer 2: 108-119, 2011.
39. Zhou J, Song S, Cen J, Zhu D, Li D and Zhang Z: MicroRNA-375 is downregulated in pancreatic cancer and inhibits cell proliferation in vitro. Oncol Res 20: 197-203, 2012.

40. Altomare DA, Tanno S, De Rienzo A, Klein-Szanto AJ, Tanno S, Skele KL, Hoffman JP and Testa JR: Frequent activation of AKT2 kinase in human pancreatic carcinomas. J Cell Biochem 87: 470-476, 2002.

41. Roy SK, Srivastava RK and Shankar S: Inhibition of PI3K/AKT and MAPK/ERK pathways causes activation of FOXO transcription factor, leading to cell cycle arrest and apoptosis in pancreatic cancer. J Mol Signal 5: 10, 2010.

42. Tomita T: Cyclin-dependent kinase (cdk6) and p16 in pancreatic endocrine neoplasms. Pathology 36: 566-570, 2004.

43. Tang LH, Contractor T, Clausen R, Klimstra DS, Du YC, Allen PJ, Brennan MF, Levine AJ and Harris CR: Attenuation of the retinoblastoma pathway in pancreatic neuroendocrine tumors due to increased cdk4/cdk6. Clin Cancer Res 18: 4612-4620, 2012. 